\title{
Aporte de mantillo y nutrientes en ecosistema semiárido de Brasil (Caatinga) bajo sistemas silvícolas
}

\section{Litter and nutrient deposition in semi-arid ecosystem of Brazil (Caatinga) under silvicultural systems}

\author{
Marcelo Silva de Lucenal*, Allyson Rocha Alves' e Ivonete Alves Bakkel
}

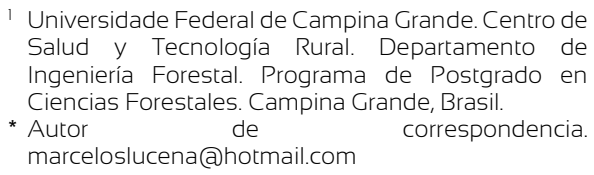

\section{RESUMEN}

El objetivo de este trabajo fue investigar el efecto de sistemas silvícolas y de los usos del suelo sobre la acumulación de mantillo y su relación con la recirculación de nutrientes al suelo, en dos áreas del bioma Caatinga, en la zona semiárida de Brasil. La primera se encuentra en la estación ecológica del Seridó; la segunda, en la hacienda Pedro Cândido. El mantillo se recolectó en los períodos lluvioso y seco, con ayuda de una trampa de $0.25 \mathrm{~m}^{2}$, con 16 repeticiones en cada área (cuatro repeticiones por sistema silvícola). El mantillo recolectado se separó en las fracciones: ramas, hojas + estructuras reproductivas y miscelánea; los valores obtenidos para cada fracción se sometieron al análisis de varianza, bajo un diseño experimental de bloques al azar. Para el análisis químico del mantillo, se analizaron muestras compuestas por las cuatro repeticiones de cada fracción referente a cada sistema silvícola, en los dos períodos. En ambos períodos, en la estación ecológica del Seridó hubo $1570 \mathrm{~kg} \mathrm{ha}^{-1}$ y $1890 \mathrm{~kg} \mathrm{ha}^{-1}$ de mantillo y $44.18 \mathrm{~kg} \mathrm{ha}^{-1}$ y $59.05 \mathrm{~kg} \mathrm{ha}^{-1}$ de nutrientes devueltos al suelo, respectivamente. En la hacienda Pedro Castillo, en ambos períodos, hubo $2320 \mathrm{~kg} \mathrm{ha}^{-1}$ y $2290 \mathrm{~kg} \mathrm{ha}^{-1} \mathrm{de}$ mantillo y $55.86 \mathrm{~kg} \mathrm{ha}{ }^{-1}$ y 61.98 $\mathrm{kg} \mathrm{ha}^{-1}$ de nutrientes devueltos al suelo, respectivamente. El mayor aporte de mantillo en la hacienda Pedro Castillo se debió a la mayor cantidad de ramas, pero esto no resultó en un mejor aporte de nutrientes. Después de 27 años de las intervenciones, no hubo influencia de los sistemas silvícolas sobre las fracciones y cantidad de nutrientes.

PALABRAS CLAVE: administración forestal; biomasa acumulada; macronutrientes, usos del suelo.

\section{ABSTRACT}

This study aimed to investigate the effect of silvicultural systems and of the uses of the soil on the accumulation of the litter, its relation with the recycling and the nutrient supply to the soil, in two areas of Caatinga, in the semi-arid region of Brazil. The first is in the Seridó ecological station; the second is on Pedro Cândido farm. The accumulated litter was collected in the rainy and dry periods with the aid of a litter trap of $0.25 \mathrm{~m}^{2}$, with 16 replicates in each area (4 replicates by silvicultural system). The litter was separated into the fractions of branches, leaves + reproductive structure and miscellaneous, and the values obtained for each fraction were submitted to analysis of variance, according to a randomized block design. For the chemical analysis of litter, samples composed by the four replicates of each fraction referring to each silvicultural system were analyzed, in both evaluated periods. In both periods, in the Seridó ecological station there were $1570 \mathrm{~kg} \mathrm{ha}^{-1}$ and $1890 \mathrm{~kg} \mathrm{ha}^{-1}$ of litter and $44.18 \mathrm{~kg} \mathrm{ha}^{-1}$ and $59.05 \mathrm{~kg} \mathrm{ha}^{-1}$ of nutrients returned to soil, respectively. In the Pedro Cândido farm, in both periods, there were $2320 \mathrm{~kg} \mathrm{ha}^{-1}$ and $2290 \mathrm{~kg} \mathrm{ha}^{-1}$ of litter and $55.86 \mathrm{~kg} \mathrm{ha}^{-1}$ and $61.98 \mathrm{~kg}$ ha-1 of nutrients recycled to the soil, respectively. The largest accumulation of litter in the Pedro Cândido farm occurred due to the greater amount of branches, but this did not result in a better supply of nutrients. After 27 years of interventions, there was no influence of silvicultural systems on the fractions and amount of nutrients.

KEYWORDS: forest management; accumulated biomass; macronutrients, land uses. 


\section{INTRODUCCIÓN}

La zona semiárida brasileña, donde prioritariamente se desarrolla el bioma Caatinga, ocupa la región nordeste de Brasil y presenta una temperatura media anual de $27^{\circ} \mathrm{C}$ y precipitación anual de $250 \mathrm{~mm}$ a $900 \mathrm{~mm}$ al año. La evapotranspiración potencial oscila entre $1500 \mathrm{~mm}$ y 2000 $\mathrm{mm}$ anuales. De la interacción de estos dos factores resulta déficit hídrico en la mayor parte del año (Prado, 2003; Alves, Araújo y Nascimento, 2009; Sampaio, 2010). Según Giulietti et al. (2004), el bioma Caatinga corresponde a una vegetación con especies xerófilas, con morfología y fisiología (caducidad de las hojas, hojas pequeñas, reservas de agua en las raíces) adaptadas a las deficiencias hídricas, con predominancia de arbustos y árboles pequeños y hierbas efímeras. Los recursos forestales de la vegetación del bioma Caatinga son relevantes para la economía local, los cuales se obtienen mediante la utilización de sistemas silvícolas o por medio de acciones basadas en un régimen extractivo y exploratorio.

En la óptica de la administración forestal, los sistemas silvícolas son operaciones diseñadas para conducir un bosque a un nuevo ciclo de producción. Ellos cubren actividades de la cosecha (corte selectivo, corte general, etc.), tratamientos silviculturales aplicados a la vegetación remanente y conducción de la regeneración natural, para tener producciones sostenibles de los bienes y servicios que los bosques pueden ofrecer (Souza y Soares, 2013). En lo que se refiere a la relación entre los bosques y la acumulación de mantillo y el depósito de nutrientes al suelo, se sabe que los estudios de recirculación y acumulación de mantillo, junto con investigaciones sobre el aporte de nutrientes, ayudan a comprender el funcionamiento del ecosistema. El depósito de nutrientes está relacionado con la dinámica del mantillo, además de ser un importante mecanismo de transferencia de nutrientes al suelo, lo que incide directamente en la producción primaria de los ecosistemas forestales (Souza y Davide, 2001; Santana, 2005; Souto, 2006; Selle, 2007).

Aunque se realizan trabajos para obtener conocimiento sobre la dinámica de la acumulación del mantillo y del aporte de nutrientes en el bioma Caatinga
(Souto, 2006; Alves, Souto, Souto y Holanda, 2006; Lopes, Andrade, Lobato, Palácio y Arraes, 2009; Silva, 2014; Lima, Fernandes, Fernandes y Matricardi, 2015) son pocas las investigaciones acerca de la influencia de sistemas silvícolas sobre la acumulación y depósito de nutrientes en el suelo. El entendimiento sobre el mantillo y la cantidad de nutrientes reciclados es importante para la recuperación de zonas degradadas, proyectos de reforestación o recuperación de bosques y la manutención de la productividad de los bosques (Santana y Souto, 2011).

Así, es necesario afirmar que ese conocimiento es esencial para el establecimiento de prácticas de administración forestal de bajo impacto, principalmente cuando se considera el uso de diferentes sistemas silvícolas y distintas formas de ocupación de áreas de bosques nativos, especialmente considerando el mantenimiento de la productividad y la sostenibilidad.

\section{OBJETIVOS}

Este trabajo tuvo como objetivo investigar el efecto de los sistemas silvícolas y de los usos del suelo sobre la acumulación del mantillo sobre el suelo y evaluar la relación del mantillo acumulado con la concentración y la deposición de nutrientes al suelo en el semiárido de Brasil.

\section{MATERIALES Y MÉTODOS}

\section{Sitio de estudio}

El estudio se realizó en dos zonas vecinas, situadas en la parte suroeste del estado de Rio Grande do Norte, Brasil, ubicadas en la ciudad Serra Negra do Norte. La primera se encuentra en la estación ecológica del Seridó (4 hectáreas de área experimental), entre las coordenadas $06^{\circ} 35^{\prime}$ y $06^{\circ}$ $40^{\prime}$ S, y $37^{\circ} 20^{\prime}$ y $37^{\circ} 39^{\prime} \mathrm{O}$ (Datum SAD 69). La segunda está localizada en una propiedad privada: hacienda Pedro Cândido, contigua a la estación ecológica del Seridó y posee un área experimental de 2.5 hectáreas.

El clima de la región experimental, según la clasificación de Köppen (1996), es semiárido del tipo BsW'h'. De acuerdo con la estación de observación meteorológica ecológica del Seridó, el promedio anual de la 
temperatura es de $30.7^{\circ} \mathrm{C}$ y la máxima y mínima ocurren en octubre $\left(31.0^{\circ} \mathrm{C}\right)$ y febrero $\left(29.3^{\circ} \mathrm{C}\right)$, respectivamente. La humedad es de aproximadamente $50 \%$. La precipitación es variable, con promedio histórico de $733 \mathrm{~mm}$, concentrándose básicamente entre los meses de enero y abril (Amorim, Sampaio y Amorim, 2005; Santana, Santana Júnior, Barreto y Ferreira, 2016). La exposición solar alcanza 2800 horas anuales.

Según la clasificación de suelos de la Empresa Brasileña de Investigación Agropecuaria [Embrapa] (2013), los suelos en la región experimental son Luvissolos Crómicos, constituidos de material mineral poco intemperizado, poco profundos y saturación por base en torno a 80\%. También se registró la presencia de Neosolos Litólicos y Vertisuelos (Ministerio de Medio Ambiente [MMA], 2004). La tabla 1 presenta los valores medios de los atributos químicos del suelo, recolectados en las parcelas de los sistemas silvícolas.

La vegetación del Seridó es un tipo hiperxerófilo del bioma Caatinga, con aspecto de vegetación arbóreoarbustiva esparzo, con árboles de pequeño porte (de $4 \mathrm{~m}$ a $5 \mathrm{~m}$ de altura media y medias de diámetro, medido a $1.3 \mathrm{~m}$ a partir del suelo, de $4.0 \mathrm{~cm}$ ), con presencia de cactáceas y un estrato herbáceo estacional, casi totalmente restringido a la estación lluviosa. En lugares con mejores condiciones edáficas y más preservadas ocurren árboles de mayores diámetros y alturas. Estudios plantearon la hipótesis de que la vegetación del Seridó es una tipología con baja diversidad florística con relación a otras zonas del bioma Caatinga (Amorim, Sampaio y Amorim, 2005; Costa, Oliveira, Accioly y Silva, 2009; Lima \& Coelho, 2015).

\section{Información sobre las zonas experimentales y los sistemas silvícolas}

En las zonas de estudio, en 1989, se instaló un experimento con sistemas silvícolas para evaluar la regeneración natural de la vegetación. Estos sistemas silvícolas fueron los tratamientos utilizados en esta investigación. El experimento se constituyó en un delineamiento estadístico en bloques al azar y consistió en cuatro sistemas silvícolas (tratamientos) con cuatro repeticiones en dos bloques, según el siguiente modelo estadístico: yij $=\mu+b j+\tau i+$ eij; yij $=$ observación referente al tratamiento i en el bloque j; $\mu=$ media general (constante común a todas las observaciones); $\mathrm{bj}=$ efecto del j-ésimo bloque; $\tau \mathrm{i}=$ efecto del i-ésimo tratamiento; eij = error aleatorio.

TABla 1. Promedios de los atributos químicos del suelo ( $\mathrm{pH}$, suma de bases -SB, capacidad de intercambio de cationes $\mathrm{T} \%$, saturación por bases - V\%) y los promedios de los elementos $\mathrm{P}$ y $\mathrm{Ca} \mathrm{Mg}, \mathrm{K}$, $\mathrm{Na}$ y $\mathrm{H}+\mathrm{Al}$ en relación con las parcelas de los sistemas silvícolas y los bloques, Serra Negra do Norte-RN, Brasil.

\begin{tabular}{|c|c|c|c|c|c|c|c|c|c|c|}
\hline \multirow{2}{*}{$\begin{array}{l}\text { Sistema } \\
\text { Silvícola }\end{array}$} & \multicolumn{10}{|c|}{ Parámetros Evaluados } \\
\hline & $\mathrm{pH}$ & $\begin{array}{c}P \\
\left(\mathrm{mg}^{-\mathrm{dm}^{-3}}\right)\end{array}$ & $\begin{array}{c}\mathrm{Ca} \\
\left(\mathrm{mg}^{-3 m^{-3}}\right)\end{array}$ & $\begin{array}{c}\mathrm{Mg} \\
\left(\mathrm{cmolc} \mathrm{dm}^{-3}\right)\end{array}$ & $\begin{array}{c}\mathrm{K} \\
\left(\mathrm{cmolc}_{\mathrm{cm}}^{-3}\right)\end{array}$ & $\begin{array}{c}\mathrm{Na} \\
\left(\mathrm{cmolc}_{\mathrm{dm}}^{-3}\right)\end{array}$ & 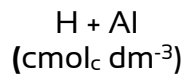 & $\begin{array}{c}\mathrm{SB} \\
\left(\mathrm{cmol}_{\mathrm{c}} \mathrm{dm}^{-3}\right)\end{array}$ & $\mathrm{T} \%$ & $\vee \%$ \\
\hline CG & $5.25 a$ & $2.99 a$ & $5.17 a$ & $2.87 \mathrm{a}$ & $0.18 a$ & $0.22 a$ & $1.57 a$ & $8.44 a$ & $10.02 a$ & $82.3 a$ \\
\hline $\mathrm{CS}_{+8}$ & $5.32 a$ & $2.40 a$ & $5.42 a$ & $3.29 \mathrm{a}$ & $0.17 a$ & $0.23 a$ & $1.60 a$ & $9.13 a$ & $10.72 a$ & $84.3 a$ \\
\hline CGQ & $5.42 \mathrm{a}$ & $2.55 a$ & $5.95 a$ & $3.40 \mathrm{a}$ & $0.19 a$ & $0.24 a$ & $1.50 a$ & $9.78 a$ & $11.28 a$ & $86.5 a$ \\
\hline CGDQ & $5.42 \mathrm{a}$ & $3.10 a$ & $6.04 a$ & $3.21 \mathrm{a}$ & $0.15 a$ & $0.32 a$ & $1.91 a$ & $9.72 \mathrm{a}$ & $11.64 a$ & 84.3a \\
\hline & & & & & Bloques & & & & & \\
\hline EES & $5.53 a$ & $3.04 a$ & $5.40 a$ & $2.98 \mathrm{a}$ & $0.19 a$ & $0.22 b$ & $1.63 a$ & $8.79 a$ & $10.43 a$ & 83.7a \\
\hline FPC & $5.18 b$ & $2.48 a$ & $5.89 a$ & $3.40 \mathrm{a}$ & $0.16 \mathrm{a}$ & $0.29 a$ & $1.66 a$ & $9.75 a$ & $11.41 a$ & $84.4 a$ \\
\hline
\end{tabular}

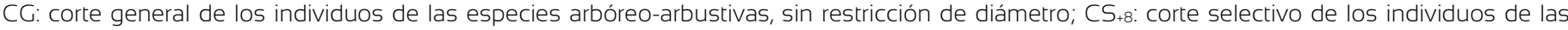

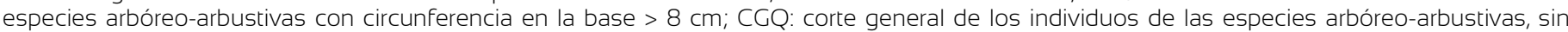

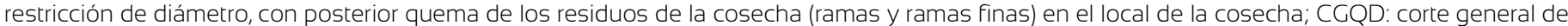

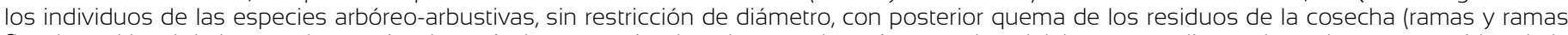

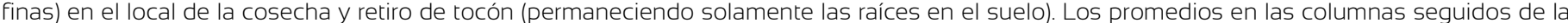
misma letra no difieren entre sí por la prueba de Tukey al nivel de $5 \%$ de significancia $(P<0.05)$. 
El diseño experimental fue en bloques debido a la posible influencia de las diferencias de uso de las áreas. En la Estación Ecológica del Seridó, el pastoreo de ganado bovino, caprino y ovino fue suspendido en 1982, año de la instalación de la unidad de conservación. En la Hacienda Pedro Cândido, por otro lado, el pastoreo siguió siendo practicado antes y durante la realización del experimento.

Los sistemas silvícolas (tratamientos) utilizados fueron: CG: corte general de todos los individuos de las especies arbóreo-arbustivas, sin restricción de diámetro; $\mathrm{CS}_{+8}$ : corte selectivo de los individuos de las especies arbóreoarbustivas con circunferencia en la base - CEB $>8 \mathrm{~cm}$ (la altura de la CEB era $20 \mathrm{~cm}$ sobre el suelo); CGQ: corte general de todos los individuos de las especies arbóreoarbustivas, sin restricción de diámetro, con posterior quema de los residuos de la cosecha (ramas y ramas finas) en el local de la cosecha (en cada una de las parcelas); CGQD: corte general de todos los individuos de las especies arbóreo-arbustivas, sin restricción de diámetro, con posterior quema de los residuos de la cosecha (ramas y ramas finas) en el local de la cosecha y retiro de tocón (permaneciendo las raíces en el suelo).

\section{Recolección de muestras de mantillo}

El mantillo acumulado en la superficie del suelo se recolectó en los períodos lluvioso y seco, en marzo y octubre de 2016, respectivamente. Para ello, se recolectó una muestra de mantillo dentro de cada parcela de $400 \mathrm{~m}^{2}$, totalizando 16 muestras por área, siendo cuatro para cada sistema silvícola evaluado (Fig. 1).

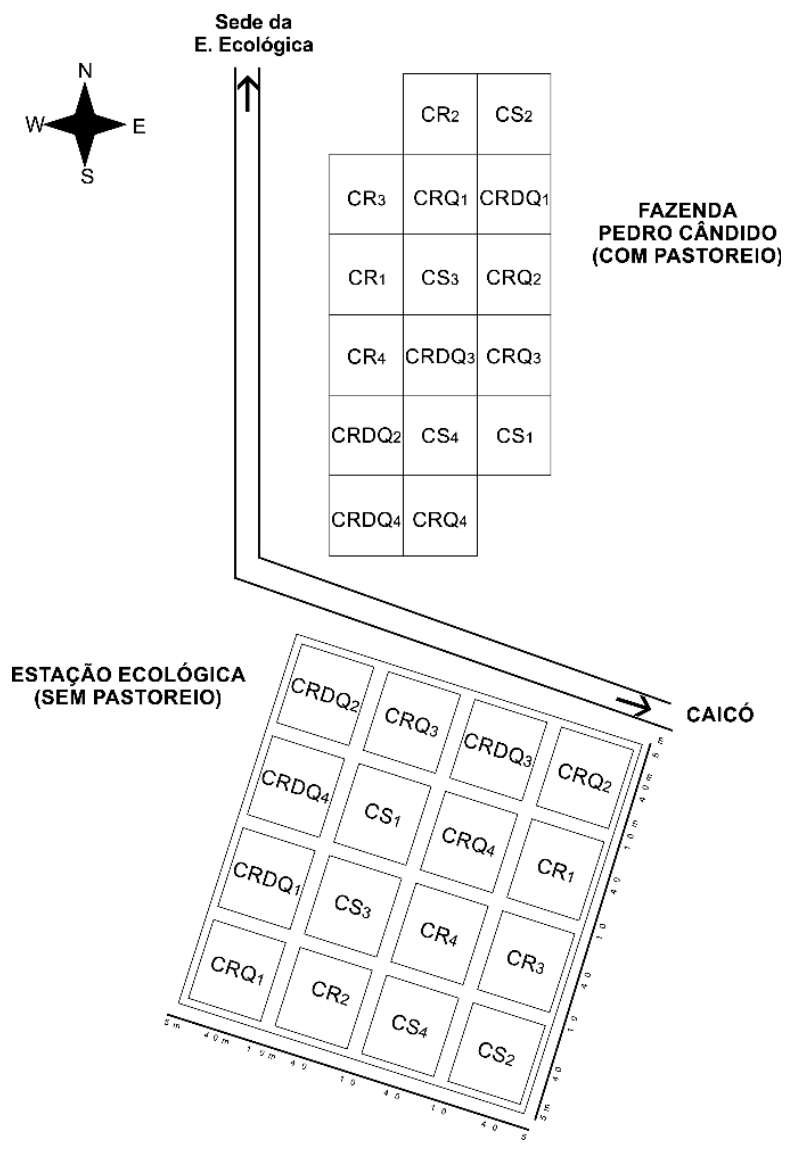

FIGURA 1. Disposición de las parcelas del experimento en la estación ecológica del Seridó y Hacienda Pedro Cândido, Serra Negra do Norte-RN. (Fuente - Meunier \& Carvalho, 2000) 
Las muestras se recolectaron con un molde flotado de $0.5 \mathrm{~m} \times 0.5 \mathrm{~m}$, lanzado al azar dentro de cada parcela. El mantillo se acondicionó en bolsas etiquetadas, separado en las fracciones hojas + estructuras reproductivas (hojas, pecíolo, flores, frutos y semillas), ramas (ramas, partes leñosas de todas las dimensiones y cáscaras) y miscelánea (material de origen vegetal y animal no identificable, en varias etapas de descomposición).

Las fracciones del mantillo se secaron previamente al aire libre y posteriormente en una estufa de secado, con circulación forzada de aire a $65^{\circ} \mathrm{C}$, durante 24 horas. Cada fracción referente a las parcelas de los sistemas silvícolas de las dos áreas fue pesada en balanza (resolución de $0.01 \mathrm{~g}$ ). Se estimó la cantidad de mantillo en cada sistema silvícola y área, por período de recolección y para cada fracción. Los valores obtenidos para cada fracción acumulada por recolección se convirtieron a kilogramos por hectárea. Los datos referentes a las tres fracciones se organizaron para cada sistema silvícola (tratamientos), dentro de cada período de recolección, y se sometieron al análisis de varianza (ANOVA). En dicho análisis, se probó la media de cuatro repeticiones de cada una de las fracciones en cada tratamiento. Se realizó la prueba de Tukey a 5\% de significancia $(\mathrm{P}<0.05)$, con el software Action Stat $3 \mathrm{y}$ Statistica 11, según un diseño experimental en bloques al azar. Previamente, los datos se transformaron mediante la operación de Box-Cox.

\section{Análisis químico del mantillo}

Los contenidos de las tres fracciones se molieron en molino tipo Willey (partículas de $0.1 \mathrm{~mm}$ ); posteriormente, se confeccionaron muestras homogéneas para cada sistema silvícola, por medio de la mezcla del material triturado referente a las cuatro repeticiones de cada fracción en cada sistema silvícola (tratamiento).Con ello se obtuvo una muestra general, en ambas áreas y períodos.

El análisis químico se realizó en el Laboratorio de Fertilidad del Suelo y Nutrición de Plantas, Sector de Suelos de la Universidad Federal Rural del Semiárido. El nitrógeno se determinó por digestión sulfúrica y fue cuantificado por el método Kjeldahl (Embrapa, 1997). Los demás elementos se obtuvieron a partir de la digestión nítrica en hornos de microondas, y sus determinaciones se realizaron por espectrofotometría para fósforo, fotometría de llamas para potasio y espectrofotómetro de absorción atómica para calcio y magnesio (Embrapa 1997). La concentración se expresó en gramos de nutrientes por kilogramo de mantillo. Las cantidades de nutrientes depositados en el suelo (CNRS), en kilogramos por hectárea, en ambas áreas y períodos, se obtuvieron mediante las siguientes expresiones:

$$
\begin{aligned}
C N R S=C(N)+C(P)+C(K)+C(C a)+C(M g) & {[1] } \\
C_{(N)} & =\left(\frac{C N x S}{1000}\right) \times H A S \\
C_{(P)} & =\left(\frac{C P x S}{1000}\right) \times H A S \\
C_{(K)} & =\left(\frac{C K x S}{1000}\right) \times H A S \\
C_{(C a)} & =\left(\frac{C C a x S}{1000}\right) \times H A S \\
C_{(M g)} & =\left(\frac{C M g x S}{1000}\right) \times H A S \\
H A S & =(T g+T f+T m)
\end{aligned}
$$

donde:

CNRS = Cantidad de nutrientes depositados en el suelo en cada sistema silvícola

$C_{(\mathrm{N})}=$ masa neta de nitrógeno

$C_{(P)}=$ masa neta de fósforo

$C_{(K)}=$ masa neta de potasio

$C_{(C a)}=$ masa neta de calcio

$C_{(M g)}=$ masa de magnesio

$C N \times S=$ Concentración de $\mathrm{N}^{*}$

$C P \times S=$ Concentración de $\mathrm{P}^{*}$

$C K \times S=$ Concentración de $\mathrm{K}^{*}$

$C C a \times S=$ Concentración de $\mathrm{Ca}^{*}$ 
$C M g \times S=$ Concentración de $\mathrm{Mg}^{*}$

$H A S=$ Cantidad de mantillo acumulada sobre el suelo por cada sistema silvícola $\left(\mathrm{kg} \mathrm{ha}^{-1}\right)$

$\mathrm{Tg}=$ Total estimado de la fracción de ramas en cada sistema silvícola $\left(\mathrm{kg} \mathrm{ha}^{-1}\right)$

$T f=$ Total estimado de la fracción hojas + estructuras reproductivas en cada sistema silvícola $\left(\mathrm{kg} \mathrm{ha}^{-1}\right)$

Tm $=$ Total estimado da fracción miscelánea en cada sistema silvícola $\left(\mathrm{kg} \mathrm{ha}^{-1}\right)$

* procedentes de la mezcla de las tres fracciones para la cantidad total del contenido de mantillo de las cuatro repeticiones de cada sistema silvícola, expresadas en gramo por kilogramo.

Se realizó la comparación de la masa neta de nutrientes (concentración en gramos de nutrientes por kilogramo de mantillo) entre los sistemas silvícolas en cada período, la concentración de un mismo nutriente entre las áreas en el mismo período y la comparación de la masa neta nutriente entre los períodos evaluados, para ello se realizó la prueba no paramétrica de Wilcoxon $(\mathrm{P}<0.05)$.

La cantidad de nutrientes que retornan al suelo (CNRS), proporcionada por los sistemas silvícolas, dentro de cada período, se evaluó por comparaciones mutuas por la prueba de Kruskal-Wallis a 5\% de significancia (P < 0.05). La cantidad de cada nutriente que retorna al suelo fue comparada entre las áreas dentro de cada período considerado, donde se utilizó una prueba no paramétrica, la de Wilcoxon $(\mathrm{P}<0.05)$.

\section{Resultados}

En el período lluvioso, el total de mantillo acumulado, referente a la suma de las dos áreas de estudio, fue $3890 \mathrm{~kg}$ ha ${ }^{-1}$, la Hacienda Pedro Cândido presentó la mayor acumulación, especialmente por la mayor cantidad de la fracción de ramas. En el período seco, el total de mantillo acumulado fue $4180 \mathrm{~kg} \mathrm{ha}^{-1}$ (Tabla 2).

En el período lluvioso, en la estación ecológica del Seridó, la fracción ramas representó 59.24\% del total recogido, seguida por la fracción miscelánea con $24.20 \%$. En la hacienda Pedro Cândido, la fracción ramas correspondió a $76.3 \%$ del total recogido, seguida por la fracción miscelánea, con $14.2 \%$. En el período seco, se constató que en la estación ecológica del Seridó la fracción hojas + estructuras reproductivas tuvo mayor participación, correspondiendo cerca de $38.09 \%$ del total, seguida por la fracción ramas que fue responsable de $34.49 \%$. En la hacienda Pedro Cândido, la fracción ramas correspondió a $52.40 \%$ del total. A continuación, con cerca de 30.13\%, vino la fracción hojas + estructuras reproductivas.

Se constató que, en los períodos lluvioso y seco, no se observaron diferencias significativas entre los sistemas silvícolas, en relación con las tres fracciones evaluadas. Sin embargo, para la fracción ramas, hubo diferencia significativa entre los locales, donde la hacienda Pedro Cândido presentó el mayor promedio de valores acumulados por hectárea. Así, se evidencia que 27 años después de las intervenciones, los sistemas silvícolas no promovieron diferencias significativas sobre la acumulación de las fracciones evaluadas. Sin embargo, las diferentes formas de uso de las áreas propiciaron la diferencia estadística para la fracción ramas (Tabla 3).

Tanto en el período lluvioso como en el seco, las concentraciones de los macronutrientes no variaron entre las áreas ni entre los sistemas silvícolas. Tampoco hubo diferencia en relación a un mismo nutriente dentro de cada período en una misma área. Pero, se observaron mayores concentraciones nitrógeno, potasio y calcio, en ambos períodos, en la estación ecológica del Seridó, mientras que magnesio y fósforo presentaron mayores valores en la hacienda Pedro Cândido en el período seco.

A pesar de que no hay diferencia significativa entre las áreas, en la estación ecológica del Seridó, en ambos períodos, mientras que las concentraciones de nitrógeno y potasio fueron uniformes entre los sistemas silvícolas, los elementos fósforo, calcio y magnesio presentaron considerable variación. En el período seco hubo un sensible aumento de potasio y magnesio. Por otro lado, en la hacienda Pedro Cândido, en el período lluvioso, las concentraciones de nitrógeno, potasio y magnesio fueron uniformes entre los sistemas silvícolas. En el período seco, solo el calcio presentó uniformidad (Tabla 4). 
TABLA 2. Estimación de la masa seca total $\left(\mathrm{kg} \mathrm{ha}^{-1}\right)$ y la desviación estándar $\left(\mathrm{kg} \mathrm{ha}^{-1}\right)$ de las fracciones recogidas en los períodos lluvioso y seco, en los sistemas silvícolas en la estación ecológica del Seridó y Hacienda Pedro Cândido, Serra Negra do Norte-RN.

\begin{tabular}{|c|c|c|c|}
\hline \multirow{2}{*}{ Estación Ecológica del Seridó } & \multicolumn{3}{|c|}{ Período lluvioso } \\
\hline & Hojas + estructuras reproductivas & Ramas & Miscelánea \\
\hline Corte general - CG & $60 \pm 20.43$ & $160 \pm 16.10$ & $70 \pm 5.28$ \\
\hline Corte selectivo - CS & $70 \pm 22.50$ & $410 \pm 81.40$ & $160 \pm 14.18$ \\
\hline Corte general con quema - CGQ & $70 \pm 26.20$ & $190 \pm 28.10$ & $70 \pm 4.63$ \\
\hline Corte general con destoca y quema - CGQD & $60 \pm 3.00$ & $170 \pm 64.50$ & $80 \pm 25.67$ \\
\hline \multirow{2}{*}{ Total } & 260 & 930 & 380 \\
\hline & \multicolumn{3}{|c|}{1570} \\
\hline Hacienda Pedro Cândido & \multicolumn{3}{|c|}{ Período lluvioso } \\
\hline Corte general - CG & $40 \pm 11.50$ & $500 \pm 64.50$ & $80 \pm 15.75$ \\
\hline Corte selectivo - CS & $40 \pm 13.80$ & $430 \pm 69.50$ & $40 \pm 10.97$ \\
\hline Corte general con quema - CGQ & $90 \pm 17.70$ & $350 \pm 46.80$ & $90 \pm 15.12$ \\
\hline Corte general con destoca y quema - CGQD & $50 \pm 20.80$ & $490 \pm 63.00$ & $120 \pm 37.11$ \\
\hline \multirow{2}{*}{ Total } & 220 & 1770 & 330 \\
\hline & \multicolumn{3}{|c|}{2320} \\
\hline Estación Ecológica del Seridó & \multicolumn{3}{|c|}{ Período Seco } \\
\hline Corte general - CG & $210 \pm 9.66$ & $110 \pm 13.31$ & $80 \pm 71.13$ \\
\hline Corte selectivo - CS & $200 \pm 26.98$ & $180 \pm 26.16$ & $130 \pm 17.22$ \\
\hline Corte general con quema - CGQ & $190 \pm 28.25$ & $130 \pm 23.34$ & $160 \pm 32.62$ \\
\hline Corte general con destoca y quema - CGQD & $120 \pm 17.50$ & $230 \pm 64.83$ & $150 \pm 33.47$ \\
\hline \multirow{2}{*}{ Total } & 720 & 650 & 520 \\
\hline & \multicolumn{3}{|c|}{1890} \\
\hline Hacienda Pedro Cândido & \multicolumn{3}{|c|}{ Período Seco } \\
\hline Corte general - CG & $120 \pm 11.32$ & $360 \pm 35.37$ & $110 \pm 21.28$ \\
\hline Corte selectivo - CS & $170 \pm 15.09$ & $240 \pm 37.25$ & $50 \pm 4.85$ \\
\hline Corte general con quema - CGQ & $220 \pm 34.72$ & $160 \pm 43.03$ & $90 \pm 7.21$ \\
\hline Corte general con destoca y quema - CGQD & $180 \pm 29.87$ & $440 \pm 28.79$ & $150 \pm 20.88$ \\
\hline \multirow{2}{*}{ Total } & 690 & 1200 & 400 \\
\hline & \multicolumn{3}{|c|}{2290} \\
\hline
\end{tabular}

CG: corte general de los individuos de las especies arbóreo-arbustivas, sin restricción de diámetro; CS+8: corte selectivo de los individuos de las especies arbóreo-arbustivas con circunferencia en la base $>8 \mathrm{~cm}$; CGQ: corte general de los individuos de las especies arbóreo-arbustivas, sin restricción de diámetro, con posterior quema de los residuos de la cosecha (ramas y ramas finas) en el local de la cosecha; CGQD: corte general de los individuos de las especies arbóreo-arbustivas, sin restricción de diámetro, con posterior quema de los residuos de la cosecha (ramas y ramas finas) en el local de la cosecha y retiro de tocón (permaneciendo solamente las raíces en el suelo).

En ninguna de las áreas y en ninguno de los periodos se observaron diferencias entre la cantidad de nutrientes que regresan al suelo, en función de los sistemas silvícolas evaluados. Tampoco hubo diferencia entre las cantidades de un mismo nutriente dentro de cada período en una misma área (Tabla 5).

En el período lluvioso, todos los nutrientes fueron repuestos en mayor cantidad en la hacienda Pedro Cândido.
Esta superioridad se debe a la mayor acumulación de mantillo observado en esta área. La mayor diferencia observada fue para el fósforo, con una deposición casi 2.5 veces mayor que en la estación ecológica del Seridó. En el período seco, salvo nitrógeno y potasio, los mayores valores también se registraron para la hacienda Pedro Cândido. La mayor diferencia de producción entre las áreas fue observada con relación al fósforo y al magnesio. 
TABLA 3. Valores medios de masa seco $\left(\mathrm{kg} \mathrm{ha}^{-1}\right)$ y desviación estándar $\left(\mathrm{kg} \mathrm{ha}^{-1}\right)$ de las fracciones hojas + estructuras reproductivas, ramas y mezcla, para los períodos lluvioso y seco, referentes a la media de cuatro repeticiones de cada una de las fracciones en cada tratamiento, en la estación ecológica del Seridó - EES y hacienda Pedro Cândido - HPC, Serra Negra do Norte-RN.

\begin{tabular}{|c|c|c|c|}
\hline \multicolumn{4}{|c|}{ Período lluvioso } \\
\hline \multirow{2}{*}{ Sistemas silvícolas } & \multicolumn{3}{|c|}{ Fracciones evaluadas } \\
\hline & Hojas + estructuras reproductivas & Ramas & Miscelánea \\
\hline $\mathrm{CG}^{*}$ & $12.195 \pm 5.56 \mathrm{a}$ & $81.842 \pm 22.11 \mathrm{a}$ & $18.513 \pm 3.87 a$ \\
\hline $\mathrm{CS}^{*}$ & $13.926 \pm 6.19 a$ & $104.147 \pm 24.79 a$ & $26.762 \pm 7.75 a$ \\
\hline CGQ * & $19.522 \pm 7.35 a$ & $67.464 \pm 14.71 \mathrm{a}$ & $20.036 \pm 3.75 a$ \\
\hline CGQD * & $13.825 \pm 4.98 \mathrm{a}$ & $82.342 \pm 25.57 a$ & $25.652 \pm 10.58 a$ \\
\hline \multicolumn{4}{|c|}{ Bloques } \\
\hline EES & $16.034 \pm 4.52 \mathrm{a}$ & $58.063 \pm 13.81 b$ & $25.059 \pm 4.42 \mathrm{a}$ \\
\hline HPC & $13.700 \pm 3.83 \mathrm{a}$ & $109.835 \pm 14.26 \mathrm{a}$ & $20.423 \pm 5.32 \mathrm{a}$ \\
\hline \multicolumn{4}{|c|}{ Período Seco } \\
\hline \multirow{2}{*}{ Sistemas silvícolas } & \multicolumn{3}{|c|}{ Fracciones evaluadas } \\
\hline & Hojas + estructuras reproductivas & Ramas & Miscelánea \\
\hline$C G^{*}$ & $41.206 \pm 5.45 a$ & $58.967 \pm 14.88 \mathrm{a}$ & $23.431 \pm 5.45 a$ \\
\hline $\mathrm{CS}^{*}$ & $45.404 \pm 7.30 \mathrm{a}$ & $51.873 \pm 10.88 a$ & $22.487 \pm 5.80 a$ \\
\hline CGQ* & $51.031 \pm 10.42 a$ & $36.565 \pm 11.39 a$ & $31.343 \pm 8.25 a$ \\
\hline CGQD * & $37.225 \pm 8.55 a$ & $83.320 \pm 19.10 a$ & $37.883 \pm 9.13 \mathrm{a}$ \\
\hline \multicolumn{4}{|c|}{ Bloques } \\
\hline EES * & $44.770 \pm 5.43 a$ & $40.731 \pm 8.89 b$ & $32.448 \pm 5.99 a$ \\
\hline HPC * & $42.663 \pm 5.96 a$ & $74.631 \pm 10.74 \mathrm{a}$ & $25.124 \pm 4.20 \mathrm{a}$ \\
\hline
\end{tabular}

* Los promedios, en las columnas, seguidos por la misma letra no difieren estadísticamente entre sí según la prueba de Tukey a 5\% de significancia ( $\mathrm{P}<$ 0.05); CG: corte general de los individuos de las especies arbóreo-arbustivas, sin restricción de diámetro; CS+8: corte selectivo de los individuos de las especies arbóreo-arbustivas con circunferencia en la base $>8 \mathrm{~cm}$; CGQ: corte general de los individuos de las especies arbóreo-arbustivas, sin restricción de diámetro, con posterior quema de los residuos de la cosecha (ramas y ramas finas) en el local de la cosecha; CGQD: corte general de los individuos de las especies arbóreo-arbustivas, sin restricción de diámetro, con posterior quema de los residuos de la cosecha (ramas y ramas finas) en el local de la cosecha y retiro de tocón (permaneciendo solamente las raíces en el suelo).

\section{DISCUSIÓN}

El valor registrado para el total acumulado en las áreas estudiadas y en los dos períodos es similar al calculado por Souza, Pinto, Nunes, Leonardo y Souto (2016). Estos autores, evaluando la acumulación de mantillo en tres zonas con diferentes regímenes de manejo: I) un área preservada, II) otra explotada con manejo sostenible de leña (sometida a corte general de toda la vegetación arbóreo-arbustiva) y III) una que había sido explotada a un año con corte general, registraron para las tres áreas, respectivamente, las cantidades de mantillo acumulada: $3397 \mathrm{~kg} \mathrm{ha}^{-1} 4229 \mathrm{~kg} \mathrm{ha}^{-1}$ y $3951 \mathrm{~kg} \mathrm{ha}^{-1}$. Se observa que el mayor valor para las áreas II y III se debe al depósito de los residuos del corte.
Alves (2011), evaluando la acumulación del mantillo en el bioma Caatinga, en dos áreas con diferentes etapas sucesivas (regeneración después de 22 años de corte general y área preservada), afirma que, en el período lluvioso, la masa media del mantillo acumulado fue $6100 \mathrm{~kg} \mathrm{ha}^{-1} \mathrm{y}$ $11600 \mathrm{~kg} \mathrm{ha}^{-1}$, respectivamente. En el período seco, los valores son de $5300 \quad \mathrm{~kg} \quad \mathrm{ha}^{-1}$ y $10 \quad 000 \quad \mathrm{~kg} \quad \mathrm{ha}^{-1}$, respectivamente, para las dos áreas.

Se constata que las alteraciones promovidas por las distintas formas de uso de los bosques no se restringen a poco después de las intervenciones, como ha demostrado Souza et al. (2016), sino que perduran por un considerable período, como demuestran Alves (2011) y los datos de la presente investigación. 
TABLA 4. Masa neta media de nutrientes (concentración en gramos de nutrientes por kilogramo de mantillo) registrada en el mantillo en los períodos lluviosos y seco en la estación ecológica del Seridó (EES) y en la hacienda Pedro Cândido (HPC), Serra Negra do Norte-RN.

\begin{tabular}{|c|c|c|c|c|c|c|c|c|c|c|c|c|c|c|}
\hline \multirow{2}{*}{$\begin{array}{l}\text { Período } \\
\text { lluvioso }\end{array}$} & \multicolumn{7}{|c|}{ EES } & \multicolumn{7}{|c|}{ HPC } \\
\hline & $\mathrm{N}$ & $P$ & K & $\mathrm{Ca}$ & $\mathrm{Mg}$ & Total & Mediana & $\mathrm{N}$ & $P$ & K & $\mathrm{Ca}$ & $\mathrm{Mg}$ & Total & Mediana \\
\hline $\mathrm{CG}^{*}$ & 10.9 & 0.43 & 1.0 & 12.2 & 0.5 & 25.0 & $1 a$ & 9.6 & 0.15 & 1.0 & 15.9 & 0.4 & 27.1 & $1 a$ \\
\hline $\mathrm{CS}^{*}$ & 10.1 & 0.05 & 1.0 & 16.2 & 0.4 & 27.7 & $1 a$ & 10.5 & 0.15 & 1.0 & 13.2 & 0.4 & 25.3 & $1 a$ \\
\hline CGQ* & 10.5 & 0.05 & 1.0 & 18.1 & 0.4 & 30.1 & $1 a$ & 9.2 & 0.86 & 1.0 & 13.8 & 0.5 & 25.4 & $1 a$ \\
\hline CGQD* & 13.1 & 0.42 & 1.5 & 14.0 & 0.8 & 29.8 & $1.5 a$ & 9.6 & 0.25 & 1.0 & 8.0 & 0.5 & 19.4 & $1 \mathrm{a}$ \\
\hline Total & 44.6 & 0.95 & 4.5 & 60.5 & 2.1 & 112.0 & - & 38.9 & 1.41 & 4.0 & 50.9 & 1.8 & 97.0 & - \\
\hline Mediana & $\begin{array}{c}10.7 \mathrm{~A}- \\
1\end{array}$ & $\begin{array}{c}0.4 \mathrm{~A}- \\
1\end{array}$ & $\begin{array}{l}1.0 \\
A-1\end{array}$ & $\begin{array}{c}15.1 \mathrm{~A}- \\
1\end{array}$ & $\begin{array}{c}0.45 \mathrm{~A}- \\
1\end{array}$ & - & - & $\begin{array}{c}9.6 \mathrm{~A}- \\
1\end{array}$ & $\begin{array}{c}0.2 \mathrm{~A}- \\
1\end{array}$ & $\begin{array}{l}1.0 \\
A-1\end{array}$ & $\begin{array}{c}13.5 \mathrm{~A}- \\
1\end{array}$ & $\begin{array}{c}0.45 \mathrm{~A}- \\
1\end{array}$ & - & - \\
\hline Período Seco & & & EES & & & Total & Mediana & & & $\mathrm{HPC}$ & & & Total & Mediana \\
\hline $\mathrm{CG}^{*}$ & 10.9 & 0.05 & 3.5 & 16.8 & 2.6 & 33.9 & $3.5 \mathrm{a}$ & 10.5 & 0.15 & 2.0 & 12.1 & 1.6 & 26.35 & $2.0 \mathrm{a}$ \\
\hline $\mathrm{CS}^{*}$ & 10.9 & 0.06 & 3.0 & 13.8 & 2.1 & 29.9 & $3.0 \mathrm{a}$ & 10.9 & 0.49 & 2.5 & 14.9 & 2.7 & 31.49 & $2.7 \mathrm{a}$ \\
\hline CGQ* & 10.5 & 0.08 & 3.5 & 15.4 & 1.9 & 31.4 & $3.5 \mathrm{a}$ & 11.4 & 0.11 & 4.8 & 16.2 & 3.8 & 36.31 & $4.8 \mathrm{a}$ \\
\hline $\mathrm{CGQD}^{*}$ & 11.8 & 0.21 & 3.8 & 13.2 & 1.4 & 30.4 & $3.8 \mathrm{a}$ & 2.6 & 0.13 & 2.0 & 12.7 & 1.9 & 19.33 & $2.0 \mathrm{a}$ \\
\hline Total & 44.1 & 0.40 & 13.8 & 59.2 & 8.0 & 125.5 & - & 35.4 & 0.88 & 11.3 & 55.9 & 10.0 & 113.48 & - \\
\hline Mediana & $\begin{array}{r}10.9 \\
\text { A-1 }\end{array}$ & $\begin{array}{c}0.07 \\
\text { A-1 }\end{array}$ & $\begin{array}{l}3.5 \\
A-1\end{array}$ & $\begin{array}{r}14.6 \\
\text { A-1 }\end{array}$ & $\begin{array}{l}2.0 \\
A-1\end{array}$ & - & - & $\begin{array}{c}10.7 \\
\text { A-1 }\end{array}$ & $\begin{array}{l}0.14 \\
A-1\end{array}$ & $\begin{array}{c}2.25 \\
\text { A-1 }\end{array}$ & $\begin{array}{l}13.8 \\
\text { A-1 }\end{array}$ & $\begin{array}{l}2.3 \\
A-1\end{array}$ & - & - \\
\hline
\end{tabular}

Si las medianas son seguidas de la misma letra minúscula en la línea, los tratamientos no difieren entre sí en el mismo período y si las medianas son seguidas por el mismo número en la línea, los nutrientes no difieren entre sí entre las áreas en un mismo período. Si las medianas son seguidas de la misma letra mayúscula en la columna, los nutrientes no difieren entre sí por la prueba de Wilcoxon a $5 \%$ de significancia (P < 0.05 ) entre los periodos. ${ }^{*} \mathrm{CG}$ : corte general de los individuos de las especies arbóreo-arbustivas, sin restricción de diámetro; CS+8: corte selectivo de los individuos de las especies arbóreo-arbustivas con circunferencia en la base $>8 \mathrm{~cm}$; CGQ: corte general de los individuos de las especies arbóreo-arbustivas, sin restricción de diámetro, con posterior quema de los residuos de la cosecha (ramas y ramas finas) en el local de la cosecha; CGQD: corte general de los individuos de las especies arbóreo-arbustivas, sin restricción de diámetro, con posterior quema de los residuos de la cosecha (ramas y ramas finas) en el local de la cosecha y retiro de tocón (permaneciendo solamente las raíces en suelo).

La relevancia de las implicaciones de los sistemas silvícolas y de diferentes etapas sucesivas sobre la producción de mantillo de los ecosistemas forestales se da en vista de las alteraciones que las formas de manejo pueden provocar sobre la composición de especies y la densidad de individuos, consecuentemente con implicaciones en la cantidad y calidad del mantillo acumulado por unidad de área. Además, en zonas en fase inicial o intermedia de sucesión secundaria, la descomposición del mantillo puede ser más lenta, ya que las intervenciones como la apertura del dosel por el corte, la compactación/revolución o la quema del suelo pueden tener implicaciones en microorganismos descompuestos del suelo, pudiendo resultar en una menor velocidad de degradación de la biomasa depositada.

Silva (2014), considerando la descomposición del mantillo en función de diferentes etapas sucesivas en vegetación hiperxerófila de la Caatinga en el Seridó paraibano, afirma que en los estadios primario y secundario hay mayor tiempo de permanencia del mantillo sobre el suelo, en función de su menor velocidad de descomposición, y que la etapa de sucesión con menor intervención presenta reciclaje del mantillo ligeramente superior a los demás. Así, a pesar de una menor producción de mantillo, una menor capacidad de descomposición resultaría en una mayor acumulación de mantillo cuando la biomasa senescente está compuesta de material resistente a la descomposición, lo que justificaría la mayor acumulación de ramas en la hacienda Pedro Cândido. Además, en relación con el mayor valor de la fracción ramas en ambas localidades en el período lluvioso y en la hacienda Pedro Cândido en el periodo seco, se resalta también que su mayor participación está relacionada con la resistencia superior que ese tipo de material presenta a la descomposición, principalmente por el mayor contenido de lignina. 
TABLA 5. Estimación de la cantidad total de mantillo (HAS) para cada sistema silvícola, la cantidad de los nutrientes N, P, $\mathrm{K}$, Ca y $\mathrm{Mg}\left(\mathrm{kg} \mathrm{ha}^{-1}\right)$ y la cantidad de nutrientes devueltos al suelo - CNRS (kg ha-1) en los períodos lluvioso y seco, en función de los sistemas silvícolas, en la estación ecológica del Seridó (EES) y en la hacienda Pedro Cândido (HPC), Serra Negra do Norte-RN.

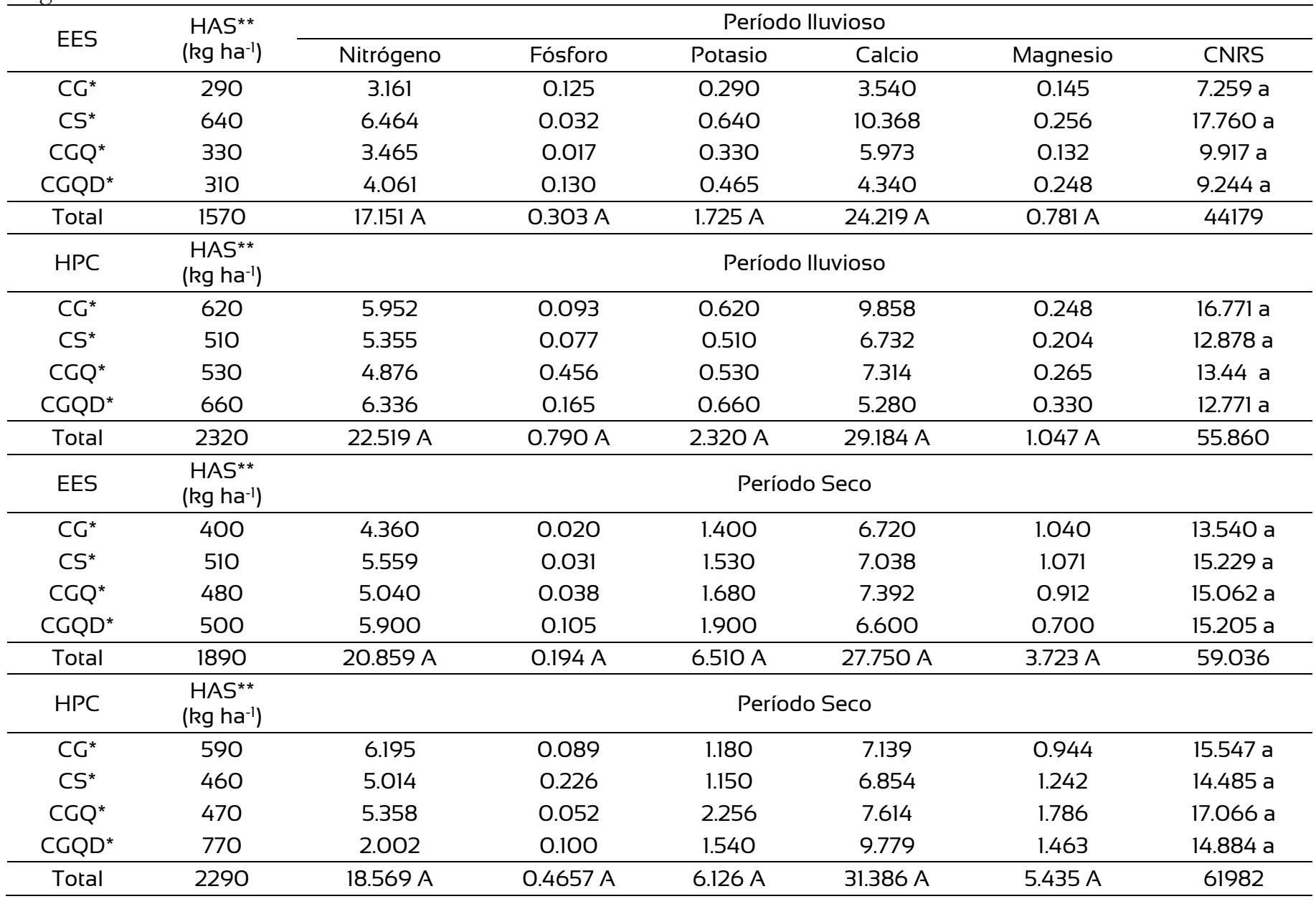

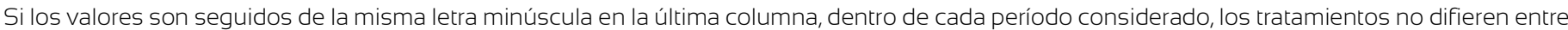

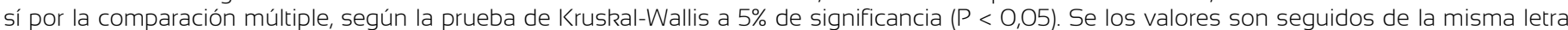

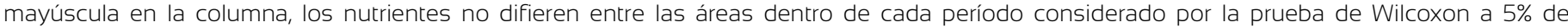

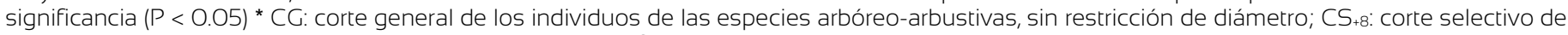

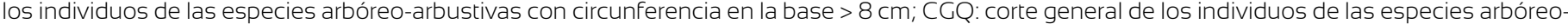

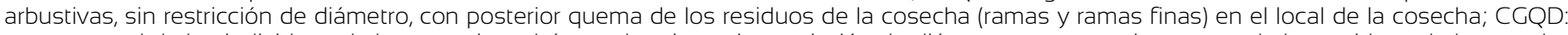

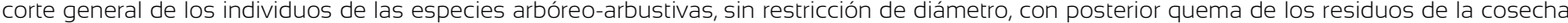
(ramas y ramas finas) en el local de la cosecha y retiro de tocón (permaneciendo solamente las raíces en el suelo).

Lima et al. (2015) afirman que la baja descomposición en el área del bioma Caatinga por ellos estudiada puede ser explicada por los altos contenidos de lignina en el mantillo. Se asegura que en el transcurso de la descomposición del mantillo, se tiene al principio una rápida pérdida de la mayoría de los compuestos hidrosolubles y una disminución lenta de compuestos fenólicos y hemicelulosa y un aumento relativo del contenido de lignina. Santana y
Souto (2011) afirman que los bajos niveles de humedad del suelo son limitantes para las actividades de organismos de descomposición del mantillo en la Caatinga. Según Lopes et al. (2009), la poca humedad del suelo en la época seca del año parece determinar la baja descomposición del mantillo sobre el suelo en ecosistemas forestales del bioma Caatinga.

En cuanto a la menor participación de las hojas en la composición de la suma total del mantillo acumulado, es 
importante considerar lo que dijeron Alves et al. (2006), respecto a que en el bioma Caatinga, el aumento de la fracción hojas en el mantillo está relacionado con una respuesta al estrés hídrico al que está sujeta la vegetación. Esta explicación justifica la menor cantidad de hojas observadas en el período lluvioso, una vez que las recolectas en este período se realizaron a principios de marzo de 2016, en la estación lluviosa.

En cuanto al período lluvioso, cuando se compara la menor persistencia sobre el suelo de la fracción hojas + estructuras reproductivas con relación a la fracción ramas, se confirma que el menor contenido de materiales más resistentes a la descomposición hace con que la fracción hojas + estructuras reproductivas sea degradada más rápidamente, presentándose en menor cantidad. Alves (2011) afirma que, como las hojas normalmente poseen baja relación carbono/nitrógeno, es de esperar una rápida mineralización de los nutrientes, poniéndolos prontamente a disposición de las raíces finas que se encuentran en las capas más superficiales de los suelos.

Con relación a los períodos estudiados, se observa que en el período seco, en las dos localidades, ocurre aumento de las fracciones hojas + estructuras reproductivas y miscelánea y disminución de la fracción ramas. El aumento porcentual de la fracción hojas + estructuras reproductivas es de aproximadamente $177 \%$ en la estación ecológica del Seridó y de $213.6 \%$ en la hacienda Pedro Cândido. A su vez, el aumento porcentual de la miscelánea es de $33.33 \%$ en la estación ecológica del Seridó y de $21.21 \%$ en la hacienda Pedro Cândido. La reducción de la fracción ramas es de orden de $30.11 \%$ en la estación ecológica del Seridó y de $32.20 \%$ en la hacienda Pedro Cândido.

Santana y Souto (2011) afirman que, en el bioma Caatinga, la producción de mantillo foliar parece estar ligada a dos circunstancias íntimamente relacionadas. La primera es el inicio del período seco, lo que ocasiona reducción de humedad del suelo. La segunda es el carácter caducifolio de las especies, en el que predomina la inmediata abscisión de las hojas para reducir las pérdidas de agua por transpiración.
Con respecto a la diferencia estadística constatada entre los lugares de estudio con relación a la fracción ramas, es necesario considerar que varios estudios (Alves et al., 2006; Souto, 2006; Lopes et al., 2009; Santana y Souto, 2011; Henriques, Souto, Souto, Santos y Lima, 2016) demuestran que la deposición de ramas ocurre con mayor intensidad en el período lluvioso, debido, principalmente, a la ocurrencia más frecuente de vientos y a la acción mecánica de la precipitación pluvial. Ante este hecho, se constata que, cuando se comparan las dos áreas del presente estudio, posiblemente, la presencia del pastoreo no controlado del ganado bovino es la variable que más se destaca para la diferenciación, promoviendo la mayor participación de la fracción ramas en el contenido del mantillo en la hacienda Pedro Cândido, ya que hay similitud entre la tipología edáfica, la fertilidad de los suelos, los atributos morfológicos del relieve y las variables climáticas.

Los cambios en la composición del mantillo en función de los usos de las áreas son observados por Lima, Leite, Aquino, Oliveira y Castro, (2010), al estudiar dos áreas de sistemas agroforestales - SAFs (6 años y 10 años, respectivamente, después de la implantación), además de un sistema de plantación ecológica y un área de agricultura tradicional, con corte y quema y un bosque nativo. Los autores afirman que, tanto en el período lluvioso como en el seco, hay diferencias significativas entre las áreas respecto a la fracción hojas y ramas. Considerando las dos fracciones y los dos períodos, el sistema agroforestal (10 años) y el bosque nativo proporcionan los mayores valores de mantillo acumulado sobre el suelo, siendo la composición más diversificada de especies arbóreas la circunstancia más importante para los resultados registrados.

Araújo-Filho (2013) afirma que el pastoreo de ganado en la Caatinga, además de influir en la compactación del suelo por el pisoteo y sus consecuentes implicaciones para la infiltración, germinación y emergencia de plántulas, elimina la parte aérea de las especies comestibles, incluyendo hojas, ramas herbáceas, flores y frutos, interfiriendo en hábitos de crecimiento y en la arquitectura de la parte aérea. Los animales al desplazarse y alimentarse 
pueden, por acción mecánica, dañar una cantidad significativa de la parte aérea.

En lo que se refiere a la concentración de macronutrientes contenidos en el mantillo, en un estudio similar, Alves et al. (2017) observaron que hay variación entre las áreas por él estudiadas y entre los períodos, seco y lluvioso para los nutrientes cuantificados. En el período lluvioso, el nitrógeno presentó un promedio de $13.6 \mathrm{~g} \mathrm{~kg}^{-1}$ $\pm 2.7 \mathrm{~g} \mathrm{~kg}^{-1}$ de mantillo en el área de regeneración y $18.6 \mathrm{~g}$ $\mathrm{kg}^{-1} \pm 3.1 \mathrm{~g} \mathrm{~kg}^{-1}$ en el área preservada. El fósforo presenta, respectivamente, para el área en regeneración y la preservada los siguientes promedios: $(1.2 \pm 0.6) \mathrm{g} \mathrm{kg}^{-1} \mathrm{y}(1.8$ $\pm 0.7) \mathrm{g} \mathrm{kg}^{-1}$. El potasio los siguientes valores, respectivamente, para las dos localidades: $(3.6 \pm 1.2) \mathrm{g} \mathrm{kg}^{-1}$ y $(4.8 \pm 1.4) \mathrm{g} \mathrm{kg}^{-1}$. Los valores observados para el calcio en las dos áreas, respectivamente, son: $(9.7 \pm 2.5) \mathrm{g} \mathrm{kg}^{-1} \mathrm{y}(14.7$ $\pm 2.6) \mathrm{g} \mathrm{kg}^{-1}$. Contrariamente a lo observado en este estudio, el magnesio es el nutriente presente en menores cantidades en el mantillo.

En cuanto a la mayor concentración de nitrógeno en la estación ecológica del Seridó en ambos períodos, es posible inferir que las cantidades superiores de miscelánea y hojas + estructuras reproductivas observadas en esta área justifican la diferencia. Ferreira et al. (2007), al estudiar el ciclo de nutrientes en bioma Caatinga, afirman que la mayor concentración de nitrógeno en el mantillo registrada en el período seco se da en función de haber un mayor depósito de hojas, siendo este un componente rico en este nutriente. Los altos niveles de este nutriente observados en el período lluvioso pueden estar relacionados con el mecanismo de transferencia del nitrógeno atmosférico al mantillo y al suelo de los bosques.

En un estudio de descomposición de nutrientes en fracciones del mantillo recogido en un área sin intervenciones en la estación ecológica del Seridó, Santana (2005) afirma que las mayores concentraciones de nitrógeno, con una diferencia significativa de 5\% para la prueba de Tukey $(\mathrm{p}<0.05)$, son observadas para la fracción miscelánea. Las hojas, especialmente de las especies Poincianella pyramidalis (Tul.) L. P. Queiroz, Aspidosperma pyrifolium Mart. y Croton blanchetianus Baill., presentan una significativa contribución.

Es importante añadir que en el presente estudio, en la estación ecológica del Seridó, Poincianella pyramidalis es la especie con mayor densidad y mayor valor de importancia. Croton blanchetianus es la cuarta en importancia y Aspidosperma pyrifolium la sexta. En la hacienda Pedro Cândido, la densidad de Poincianella pyramidalis es cerca de diez veces más pequeña en relación con la estación ecológica del Seridó, lo que puede haber contribuido a las menores cantidades de nitrógeno registradas en esa área. Aparentemente, los mayores valores de nitrógeno en la estación ecológica del Seridó pueden estar relacionados con la composición de especies, especialmente por la mayor densidad de especies leguminosas.

Además, se puede inferir que especies como Poincianella pyramidalis pueden tener un alto aprovechamiento de nitrógeno, favoreciendo el mantenimiento de comunidades en la estación ecológica del Seridó, donde hay, potencialmente, más nitrógeno disponible para las plantas.

Es importante observar que en los dos períodos y en las dos áreas, los valores de fósforo registrados son menores que los observados por Santana (2005), quien dice que en el lugar de la estación ecológica del Seridó por él estudiado, los valores de fósforo están entre $0.51 \mathrm{~g} \mathrm{~kg}^{-1} \mathrm{y}$ $1.73 \mathrm{~g} \mathrm{~kg}^{-1}$ para ramas + cáscara y miscelánea, respectivamente.

Posiblemente, por ser un elemento móvil dentro de los procesos metabólicos de las plantas, el fósforo sea redistribuido antes de la ocurrencia de la abscisión foliar, permitiendo que sea reutilizado para la formación de nuevos tejidos. Las mayores cantidades de fósforo observadas en todos los sistemas silvícolas de la hacienda Pedro Cândido, en los dos períodos, pueden ser un indicativo de que las especies presentes en esa área no son tan eficientes en la translocación y redistribución interna de este nutriente, contribuyendo al mayor contenido en el mantillo, especialmente por la mayor cantidad de hojas de las especies de Aspidosperma pyrifolium y Croton blanchetianus. Estas dos especies, de acuerdo con Santana (2005), son la 
primera y la tercera especies con mayor presencia de fósforo en las hojas, lo que refuerza lo hallado en la presente investigación.

Como el fósforo es un elemento poco móvil en el suelo, en la hacienda Pedro Cândido podría, más fácilmente, ser inmovilizado en formas indisponibles para las plantas, dificultando el progreso de especies que no sean eficientes en su absorción y utilización. Los pequeños valores de fósforo están probablemente relacionados con la mayor participación de la fracción ramas que son predominantes en las dos áreas en el período lluvioso y en la hacienda Pedro Cândido en el período seco. Santana (2005) dice que esa fracción es la que presenta la menor cantidad de este nutriente $\left(0.51 \mathrm{~g} \mathrm{~kg}^{-1}\right)$.

En el período seco, los sistemas silvícolas en las dos áreas presentan cantidades similares de potasio, con ventaja para las parcelas de la estación ecológica del Seridó. El sensible aumento del Potasio en el período seco se debe, posiblemente, al aumento del contenido de la fracción hojas y miscelánea, especialmente en la estación ecológica del Seridó, donde hay mayor participación de esas fracciones en ese período.

A pesar de que la hacienda Pedro Cândido ha presentado, en los dos períodos, menor cantidad de hojas + estructuras reproductivas que la estación ecológica del Seridó, la presencia de una mayor densidad de Aspidosperma pyrifolium contribuye, probablemente, a que no haya amplia variación en el contenido de potasio entre las áreas. De acuerdo con Santana (2005), en las hojas de dicha especie se encontró la segunda mayor cantidad de este nutriente entre las fracciones probadas, justificando afirmaciones anteriores.

El calcio es el elemento con mayor concentración en las dos áreas y en los períodos considerados. Dentro de cada área, los valores son uniformes para los sistemas silvícolas, con excepción del corte general de todos los individuos con quema de los residuos de la cosecha (ramas y ramas finas) y retiro de tocón - CGQD en el período lluvioso en la hacienda Pedro Cândido. El alto valor observado para ese nutriente se refiere a los altos valores de la fracción ramas observadas en los dos períodos y en las dos áreas. Además, Santana (2005) declara que las hojas Aspidosperma pyrifolium, Poincianella pyramidalis y Croton blanchetianus tienen una significativa concentración de calcio. Estas son las especies señaladas como las más importantes en las dos áreas de este estudio.

Con respecto al magnesio, en las dos áreas se observa que los valores no son uniformes; hay un aumento considerable para todos los sistemas silvícolas en el período seco. Esta ventaja se debe, posiblemente, al aumento del contenido de la fracción hojas + estructuras reproductivas. Sobre la variación del magnesio entre las áreas, la concentración más elevada registrada en la hacienda Pedro Cândido está relacionada con la mayor cantidad de hojas de las especies Aspidosperma pyrifolium y Croton blanchetianus, toda vez que son las más relevantes en términos de valor de importancia en esta área, teniendo en cuenta también que, Santana (2005) afirma que los mayores valores de magnesio son observados justamente para las hojas de esas especies.

En los dos períodos y en las dos áreas, el orden cuantitativo de depósito de nutrientes obedece la secuencia: calcio $>$ nitrógeno $>$ potasio $>$ magnesio $>$ fósforo. Santana (2005) y Amorim (2009) registran el mismo gradiente de concentración en mantillo muestreado en Serra Negra do Norte-RN y Petrolina-PE, respectivamente. Estas dos localidades son preservadas hace aproximadamente 30 años.

En el presente estudio, considerando la capacidad potencial de retorno de nutrientes al suelo - CNRS, en el período lluvioso, cuando se evalúan los sistemas silvícolas, se percibe que el corte selectivo de los individuos con circunferencia en la base $>8 \mathrm{~cm}$ (la altura de la CEB era $20 \mathrm{~cm}$ desde el suelo) de la estación ecológica del Seridó es el responsable de la mejor eficiencia de aporte de nutrientes, hay que regresar al suelo cerca de $60.35 \mathrm{~kg} \mathrm{ha}^{-1} \mathrm{de}$ nutrientes. La menor producción se refiere al CGDQ (que es lo corte general de los individuos de las especies arbóreoarbustivas, sin restricción de diámetro, con posterior quema de los residuos de la cosecha (ramas y ramas finas) en el local de la cosecha y retiro de tocón (permaneciendo solamente las raíces en el suelo), con $52.10 \mathrm{~kg} \mathrm{ha}^{-1}$. Es importante resaltar que este sistema silvícola presenta la 
mayor producción de biomasa de mantillo, influenciado por la gran cantidad fracción ramas.

Para Schumacher, Brun, Hernandes y König (2004), el volumen de mantillo y su composición intrínseca de nutrientes, que son devueltos al suelo por el poblamiento, tienen implicación en su capacidad productiva y en la potencialidad de recuperación ambiental, ya que se deben considerar los cambios que se producen en las características químicas de los suelos.

Si se considera la suma de cada área para los dos períodos, se puede ver que, a pesar de que la hacienda Pedro Cândido presenta la producción de mantillo $33.27 \%$ mayor que la estación ecológica del Seridó, la ventaja de retorno potencial de nutrientes al suelo fue de cerca de $14.17 \%$. Este hecho indica que las diferentes formas de uso, combinadas con las intervenciones silvícolas pueden tener implicaciones en la capacidad potencial de reciclaje de nutrientes y que una mayor cantidad de mantillo depositado sobre el suelo puede no reflejarse proporcionalmente en un retorno eficiente de nutrientes al suelo.

En ambos períodos, el hecho de no haber tenido efectos significativos de los sistemas silvícolas sobre la masa neta y la cantidad de nutrientes que retornan al suelo se debe, posiblemente, tanto a la homogeneidad como a los parámetros de densidad de individuos y la semejanza de la composición florística entre ellos en ambas áreas. A pesar de pequeñas variaciones observadas en relación con el contenido de nutrientes entre los sistemas silvícolas, áreas y períodos evaluados, la uniformidad presentada por esos parámetros refleja en una igualdad en el reciclaje de nutrientes al suelo. Sin embargo, son indispensables investigaciones más detalladas para que se pueda concluir de forma inequívoca.

\section{CONCLUSIONES}

En ambos períodos, en la hacienda Pedro Cândido, se registra mayor acumulación de mantillo.

No hay influencia de los sistemas silvícolas sobre las fracciones y cantidades de nutrientes evaluados.

En los dos períodos y en las dos áreas, el orden cuantitativo del depósito de nutrientes obedece la secuencia: calcio $>$ nitrógeno $>$ potasio $>$ magnesio $>$ fósforo.

En la estación ecológica del Seridó, la concentración más elevada de nitrógeno parece estar relacionada con la superioridad de la densidad de especies leguminosas, como Poincianella pyramidalis.

La mayor deposición de calcio en las dos áreas está relacionada con la gran cantidad de ramas presentes en el mantillo.

El corte selectivo presenta la mejor eficiencia de aporte de nutrientes al suelo.

La acumulación superior de mantillo en la hacienda Pedro Cândido no resulta proporcionalmente en una mayor eficiencia de aporte de nutrientes al suelo.

\section{RECONOCIMIENTOS}

Al ICMBIO por la autorización para los trabajos de campo en la estación ecológica del Seridó.

A la Coordinación de Perfeccionamiento de Personal de Nivel Superior (Capes) por la concesión de la beca del primer autor.

A la Red de Manejo Forestal de Caatinga por el apoyo logístico y financiero para la realización de los trabajos de campo.

A mi amigo José Alencar da Costa por la ayuda en lo relacionado a la lengua castellana.

\section{REFERENCIAS}

Alves, A. R., Souto, J. S., Souto, P. C., \& Holanda, A. C. (2006). Aporte e decomposição de serrapilheira em área de Caatinga, na Paraíba. Revista de Biologia e Ciências da terra, 6(2), 194-203. Recuperado de http:/ $/$ www.redalyc.org/articulo.oa?id $=50060212$

Alves, J. J. A., Araújo, M. A., \& Nascimento, S. S. (2009). Degradação da Caatinga: uma investigação ecogeográfica. Revista Caatinga, 22(3), 126 -135. Recuperado de http://periodicos.ufersa.edu.br/revistas/index.php/siste $\mathrm{ma} /$ article/view/560

Alves, A. R. 2011. Quantificação de biomassa e ciclagem de nutrientes em áreas de vegetação de Caatinga no município de Floresta, Pernambuco. Disertación doctoral, Universidade Federal 
Rural de Pernambuco, Recife, Brasil. Recuperado de www.tede2.ufrpe.br:8080/tede/handle/tede2/5491

Alves, A. R., Ferreira, R. L. C., Silva, J. A. A., Dubeux Júnior, J. C. B., Osajima, J. A., \& Holanda, A. C. Conteúdo de nutrientes na biomassa e eficiência nutricional em espécies da Caatinga. (2017). Ciência Florestal, 27(2), 377-390. Recuperado de https://periodicos.ufsm.br/cienciaflorestal/article/view/ $\underline{27686}$

Amorim, I. L., Sampaio, E. V. S. B., \& Araújo, E. L. (2005). Flora e estrutura da vegetação arbustivo-arbórea de uma área de caatinga do Seridó, RN, Brasil. Acta Botanica Brasilica, 19(3), 615-623. Recuperado de http://www.scielo.br/pdf/abb/v19n3/27377.pdf

Amorim, L. B. (2009). Caracterização da serapilheira em área preservada e mudanças no carbono do solo após o desmatamento sem queima. Tesis de maestria, Universidade Federal Rural de Pernambuco, Recife, Brasil. Recuperado de www.tede2.ufrpe.br:8080/tede/handle/tede2/5187

Araújo-Filho, J. A. (2013). Manejo pastoril sustentável da Caatinga. Recife-PE: Projeto Dom Helder Câmara.

Costa, T. C. C., Oliveira, M. A. J., Accioly, L. J. O., \& Silva, F. H. B. B. (2009). Análise da degradação da Caatinga no núcleo de desertificação do Seridó (RN/PB). Revista Brasileira de Engenharia Agrícola e Ambiental, 13, 961-974. Recuperado de http://www.scielo.br/pdf/rbeaa/v13s0/v13s0a20.pdf

Empresa Brasileña de Investigación Agropecuaria ([Embrapa] (1997). Manual de métodos de análise de solos. Rio de Janeiro: Centro Nacional de Pesquisa de Solos. 212p.

Recuperado

de

http://www.agencia.cnptia.embrapa.br/Repositorio/Man ual+de+Metodos 000fzvhotqk02wx5ok0q43a0ram31wtr. pdf

Empresa Brasileña de Investigación Agropecuaria [Embrapa] (2013). Sistema brasileiro de classificação de solos. 3. ed. Brasília: Embrapa. 353p.

Ferreira, R. L. C., Lira Junior, M. A., Rocha, M. S., Santos, M. V. F., Lira, M. A, \& Barreto, L. P. (2007). Deposição e acúmulo de matéria seca e nutrientes em serapilheira em um bosque de sabiá (Mimosa caesalpiniifolia Benth.). Revista Arvore, 19(3), 7-12. Recuperado de www.scielo.br/scielo.php?script $=$ sci arttext\&pid $=$ S0100$\underline{67622007000100002}$
Giulietti, A. M., Bocage Neta, A. L., Castro, A. A. J. F., GamarraRojas, C. F. L., Sampaio, E. V. S. B., Virgínio, J. F., Queiroz, L. P., Figueiredo, M. A., Rodal, M. J. N., Barbosa, M. R. V., \& Harley, R. M. (2004). Diagnóstico da vegetação nativa do Bioma Caatinga. En J. M. C. Silva, M. Tabarelli, M. T. Fonseca, \& L. V. Lins (eds). Biodiversidade da Caatinga: área e ações prioritárias para conservação (pp. 48-90). Brasília, Brasil: Ministério do Meio Ambiente.

Henriques, I. G. N., Souto, J. S., Souto, P. C., Santos, W. C., \& Lima, T. S. (2016). Acúmulo, deposição e decomposição de serapilheira sob a dinâmica vegetacional da Caatinga em Unidade de Conservação. Revista Verde de Agroecologia e Desenvolvimento Sustentável, 11(1), 84-89.

Recuperado

de

www.gvaa.com.br/revista/index.php/RVADS/article/do wnload $/ 4523 / 3869$

Köppen, W. (1996). Sistema Geográfico dos Climas (Corrêa, A. C. B. Tradutor). Recife, PE: Editora Universitária - Universidade Federal de Pernambuco.

Lima, S. S., Leite, L. F. C., Aquino, A. M., Oliveira, F. C., \& Castro, A. A. J. F. (2010). Serapilheira e teores de nutrientes em argissolo sob diferentes manejos no norte do Piauí. Revista Árvore, 34(1), 75-84. Recuperado de http:/ / www.scielo.br/scielo.php?pid=S0100$\underline{67622010000100009 \& \text { script }=\text { sci } \text { abstract\&tlng }=\text { pt. }}$

Lima, B. G., \& Coelho, M. F. B. (2015). Estrutura do componente arbustivo-arbóreo de um remanescente de Caatinga no Estado do Ceará, Brasil. Cerne, 21(4), 665-672. doi: $\underline{10.1590 / 01047760201521041807}$

Lima, R. P., Fernandes, M. M., Fernandes, M. R. M., \& Matricardi, E. A. T. (2015). Aporte e decomposição de serapilheira na Caatinga no Sul do Piauí. Floresta e Ambiente, 22(1), 42-49. doi: $10.1590 / 2179-8087.062013$

Lopes, J. F. B., Andrade, E. M., Lobato, F. A. O., Palácio, H. A. Q., \& Arraes, F. D. D. (2009). Deposição e decomposição de serapilheira em área de Caatinga.Agro@ambiente online, 3(2), 72-79. Recuperado de http://revista.ufrr.br/agroambiente/article/viewFile/252 $\not 234 \ldots$

Meunier, I. M. J., \& Carvalho, J. E. (2000). Crescimento da Caatinga submetida a diferentes tipos de corte, na região do Seridó do Rio Grande do Norte. Natal, Brasil. Projeto MMA/FAO/UTF/BRA/047. 28 p. (Boletín Técnico n.4).

Ministerio de Medio Ambiente [Mma] (2004). Plano de Manejo da Estação Ecológica do Seridó. Brasília, Brasil. Autor. Sem paginação. 
Prado, D.E. (2003). As caatingas da América do Sul. In: Leal, I.R., Tabarelli, M., \& Silva, J.M.C. (eds.). Ecologia e conservação da Caatinga. Editora Universitária, Universidade Federal de Pernambuco, Recife, Brasil.

Sampaio, E. V. S. B. (2010). Caracterização do bioma Caatinga: Características e potencialidaes. In: Gariglio, M. A., Sampaio, E. V. S B., Cestaro, L. A., \& Kageyama, P. Uso sustentável e conservação dos Recursos Florestais da Caatinga (pp. 27-42). Brasília: Serviço Florestal Brasileiro.

Santana, J.A.S. (2005). Estrutura Fitossociológica, produção de serapilheira e ciclagem de nutrientes em uma área de Caatinga no Seridó do Rio Grande do Norte. Disertación doctoral, Universidade Federal da Paraíba, Areia, Brasil. Recuperado de

http://tede.biblioteca.ufpb.br/bitstream/tede/8190/2/ar quivototal.pdf

Santana, J. A. S., \& Souto, J. S. (2011). Produção de serapilheira na Caatinga da região semiárida do Rio Grande do Norte, Brasil. Idesia, 29(2), 87-94. Recuperado de www.scielo.cl/scielo.php? script $=$ sci arttext\&pid $=$ S0718$\underline{34292011000200011}$

Santana, J. A. S., Santana Júnior, J. A. S., arreto, W. S., Ferreira, A. T. S. 2016. Estrutura e distribuição espacial da vegetação da Caatinga na Estação Ecológica do Seridó, RN. Pesquisa Florestal Brasileira, 36(88), 355-361. doi: 10.4336/2016.pfb.36.88.1002

Schumacher, M. V., Brun, E. J., Hernandes, J. I., \& König, F. G. (2004). Produção de serapilheira em uma floresta de Araucaria angustifolia (Bertol) Kuntze no município de Pinhal Grande-RS. Revista Árvore, 8(1), 29-37. Recuperado de http:/ / www.redalyc.org/articulo.oa?id=48828105

Selle, G. L. (2007). Ciclagem de nutrientes e ecossistemas florestais. Bioscience Journal, 23(4), 29-39. Recuperado de http://www.seer.ufu.br/index.php/biosciencejournal/arti cle/viewArticle/6912

Silva, A. C. F. (2014). Produção, acúmulo e decomposição de serrapilheira e repartição da precipitação pluviométrica por espécies da Caatinga. Tesis de maestria, Universidade Federal do Rio Grande do Norte, Macaíba, Brasil. Recuperado de https://repositorio.ufrn.br/jspui/handle/123456789/135 16

Souto, P. C. (2006). Acumulação e decomposição de serapilheira e distribuição de organismos edáficos em área de Caatinga na Paraíba, Brasil. Disertación doctoral, Universidade Federal da Paraíba, Areia, Brasil. Recuperado de http://tede.biblioteca.ufpb.br:8080/handle/tede/8199

Souza, J. A., \& Davide, A. C. (2001). Deposição de serrapilheira e nutrientes em uma mata não minerada e em plantações de bracatinga (Mimosa scabrella) e de eucalipto (Eucalyptus saligna) em áreas de mineração de bauxita. Revista Cerne, 7(1), 101-113. Recuperado de http:/ /www.redalyc.org/articulo.oa?id $=74470109$

Souza, A. L., \& Soares, C. P. B. (2013). Florestas Nativas: estrutura, dinâmica e manejo. Viçosa, Minas Gerais, Brasil: Ed. UFV. 322p.

Souza, M. P., Pinto, M. G. C., Nunes, A. R. V., Leonardo, F. A. P., \& Souto. J. S. (2016). Qualidade da serapilheira em área de Caatinga submetida a plano de manejo florestal. Agropecuária Cientifica no Semiárido, 12(3), 319-324. Recuperado de http://revistas.ufcg.edu.br/acsa/index.php/ACSA/article $\angle$ view $/ 856 / \mathrm{pdf}$

Manuscrito recibido el 19 de julio de 2017

Aceptado el 11 de julio de 2018

Publicado el 3 de mayo de 2019

Este documento se debe citar como:

De Lucena, M. S., Alves, A. R., \& Bakke, I, A. (2019). Aporte de mantillo y nutrientes en ecosistema semiárido de Brasil (Caatinga) bajo sistemas silvícolas. Madera y Bosques, 25(1), e2511597. doi: 10.21829/myb.2019.2511597

Madera y Bosques por Instituto de Ecología, A.C. se distribuye bajo una Licencia Creative Commons Atribución-NoComercial-Compartirlgual 4.0 Internacional. 